\title{
Vincent Majewski, Saint Colomban et les abbayes briardes. Un nouveau modèle pour l'Occident mérovingien
}

Montceaux-lès-Meaux, Éditions Fiacre, 2010, 167 p.

\section{Mickaël Wilmart}

\section{CpenEdition}

Journals

\section{Édition électronique}

URL : http://journals.openedition.org/assr/23531

DOI : 10.4000/assr.23531

ISSN : $1777-5825$

\section{Éditeur}

Éditions de l'EHESS

\section{Édition imprimée}

Date de publication : 31 décembre 2011

ISBN : 9782713223273

ISSN : 0335-5985

Référence électronique

Mickaël Wilmart, « Vincent Majewski, Saint Colomban et les abbayes briardes. Un nouveau modèle pour l'Occident mérovingien », Archives de sciences sociales des religions [En ligne], 156 | octobredécembre 2011, mis en ligne le 04 décembre 2013, consulté le 21 septembre 2020. URL : http:// journals.openedition.org/assr/23531; DOI : https://doi.org/10.4000/assr.23531

Ce document a été généré automatiquement le 21 septembre 2020.

(C) Archives de sciences sociales des religions 


\section{Vincent Majewski, Saint Colomban et les abbayes briardes. Un nouveau modèle pour l'Occident mérovingien}

Montceaux-lès-Meaux, Éditions Fiacre, 2010, 167 p.

\section{Mickaël Wilmart}

\section{RÉFÉRENCE}

Vincent MAJEWSKI, Saint Colomban et les abbayes briardes. Un nouveau modèle pour l'Occident mérovingien, Montceaux-lès-Meaux, Éditions Fiacre, 2010, 167 p.

156-73

1 Le petit nombre de pages de ce livre n'empêche pas son auteur de soulever une question importante de l'histoire du monachisme médiéval : celle de la diffusion des règles monastiques avant l'affirmation de la primauté bénédictine. Faisant preuve d'une érudition fine dans son analyse et dans sa critique de sources souvent hagiographiques ou plus tardives, V. Majewski livre ici une réflexion stimulante sur la constitution d'un maillage d'établissements réguliers dans la Gaule mérovingienne. Critiquant une lecture de l'histoire du monachisme, qu'il considère comme trop souvent téléologique car anticipant l'hégémonie de la règle bénédictine, il choisit de centrer son propos autour de la figure de saint Colomban et de ses disciples afin d'envisager « une société monastique qui se construit pour elle-même » (p. 54).

2 Moine irlandais débarquant sur le continent vers 590, Colomban passe les vingt-cinq dernières années de sa vie à tenter de diffuser son propre modèle de communauté religieuse, agissant successivement en Bretagne, en Bourgogne, en Neustrie, en Germanie et en Italie. Durant le premier tiers du vile siècle, lui et ses disciples fondent une quinzaine de monastères dont cinq dans le seul diocèse de Meaux. Ces fondations 
briardes, autour desquelles se construit le propos du livre sans toutefois s'y limiter, auxquelles il faudrait sans doute ajouter les structures créées dans les régions limitrophes comme les diocèses de Laon ou de Soissons, sont le résultat d'un lien étroit entre l'aristocratie neustrienne et l'essor de la pensée colombanienne. Colomban et, après lui, Eustaise et Walbert ont en effet su appuyer leurs efforts sur un réseau aristocratique dont les membres sont liés par le sang ou par une amitié remontant à leurs années de formation au Palais. Ce réseau a, de son côté, pu affirmer son pouvoir par les fondations pieuses tout en exprimant un attachement à une conception nouvelle du monachisme qui rencontre l'opposition virulente de l'épiscopat en place. Centrée autour de l'abbaye de Luxeuil, cette vague de fondations entend mettre en avant un modèle original basé dans un premier temps sur la règle de saint Colomban puis sur une règle mixte. La règle colombanienne s'appuie sur un pénitentiel très strict qui rend obligatoire une confession quotidienne des religieux. Ceux-ci sont donc soumis à un contrôle étroit, mais la règle, telle qu'elle nous est parvenue, fait l'impasse sur les activités rythmant la journée d'un monastère et sur certains aspects de discipline. D'où la nécessité pragmatique de recourir assez rapidement à des règles mixtes. Ainsi Walbert, avant qu'il ne prenne la tête de l'abbaye de Luxeuil, organise la vie des moniales de Faremoutiers en leur rédigeant une règle mêlant les principes de saint Colomban à ceux de saint Benoît. Ayant, par exemple, dû s'occuper de fugues de religieuses, cas non prévu par son maître, il s'inspire des préceptes bénédictins pour apporter une réponse à la question de leur réintégration. L'analyse menée par V. Majewski de cette Regula cujusdam Patris ad Virgines montre bien le passage d'une conception idéale de la vie monastique au règlement de problèmes concrets inhérents au fonctionnement d'une communauté. La conservation d'autres textes du même genre aurait sans doute permis d'expliciter encore plus finement ce phénomène de rédaction de règles mixtes dont Anne-Marie Helvétius avait déjà souligné la diversité dans le Hainaut.

En ouvrant les clôtures colombaniennes à la règle bénédictine, Eustaise et Walbert n'en proposent pas moins leur propre modèle. Les chartes de fondations se réfèrent en effet explicitement à une application de la règle à la manière de Luxeuil, conférant parfois même un droit de regard, voire de contrôle, de ses abbés sur les nouveaux établissements. Il y a bien là l'apparition d'un groupement d'abbayes autour de Luxeuil, d'inspiration colombanienne. Peut-on cependant franchir le pas et parler de congrégation comme le fait parfois, certes de façon prudente, l'auteur? Si la centralisation autour de Luxeuil peut être un argument, la disparition d'actes de la pratique ne peut qu'appeler l'historien à la retenue. Certes, Eustaise et Walbert forment à Luxeuil une partie de l'élite religieuse franque, favorisant ainsi la diffusion de leur modèle. Mais celui-ci ne se pérennise pas et laisse la place à un ordre basé sur la seule règle bénédictine, preuve que l'organisation n'était peut-être pas aussi efficace. Surtout, comme le souligne l'auteur, l'introduction de préceptes bénédictins plus modérés a sans doute commencé à affaiblir le modèle mis en place par Colomban qui avait pourtant su séduire une partie de l'aristocratie mérovingienne. Au-delà du caractère pragmatique de l'évolution des règles, nous sommes certainement aussi face à un changement des conceptions religieuses que les sources, lacunaires pour cette période, ne permettent malheureusement pas d'éclairer davantage. 